\title{
In Vitro Gynogenesis and Flow Cytometry Analysis of the Regenerated Haploids of Black Cumin (Nigella sativa)
}

\author{
Mohammed Elsayed El-Mahrouk ${ }^{1}$ \\ Department of Horticulture, Faculty of Agriculture, Kafrelsheikh University, \\ Kafr El-Sheikh 33516, Egypt
}

Mossad K. Maamoun

Breeding Research Department for Vegetables Crops, Aromatic \& Medicinal Plants, Horticultural Research Institute, Agriculture Research Center, Giza, Egypt

\author{
Antar Nasr EL-Banna \\ Genetics Department, Faculty of Agriculture, Kafrelsheikh University, Kafr \\ El-Sheikh 33516, Egypt
}

Soliman A. Omran

Breeding Research Department for Vegetables Crops, Aromatic \& Medicinal Plants, Horticultural Research Institute, Agriculture Research Center, Giza, Egypt

\section{Yaser Hassan Dewir}

Department of Horticulture, Faculty of Agriculture, Kafrelsheikh University, Kafr El-Sheikh 33516, Egypt; and Plant Production Department, P.O. Box 2460, College of Food and Agriculture Sciences, King Saud University, Riyadh 11451, Saudi Arabia

\section{Salah El-Hendawy}

Plant Production Department, P.O. Box 2460, College of Food and Agriculture Sciences, King Saud University, Riyadh 11451, Saudi Arabia; and Agronomy Department, Faculty of Agriculture, Suez Canal University, Ismailia 41522, Egypt

Additional index words. gynogenesis, haploids, organogenesis

\begin{abstract}
In vitro ovule culture could be used to generate homozygous lines through the production of haploid plants. The present study reports on in vitro regeneration and production of haploid plants through ovule cultures and identification of the regenerated haploids using flow cytometry. The ovules were cultured on Murashige and Skoog (MS) medium supplemented with different concentrations of 6-benzyladenine (BA), kinetin (Kin), 2,4-dichlorophenoxyacetic acid (2,4-D), and naphthalene acetic acid (NAA) at 0 , $0.5,1$, and $2 \mathrm{mg} \cdot \mathrm{L}^{-1}$ for their gynogenesis. Among different plant growth regulators (PGRs) tested, 2,4-D at $2 \mathrm{mg} \cdot \mathrm{L}^{-1}$ produced direct gynogenesis. The highest callogenesis percentage $(100 \%)$ was obtained on $M S$ medium containing $1 \mathrm{mg} \cdot \mathrm{L}^{-1}$ 2,4-D and $2 \mathrm{mg} \cdot \mathrm{L}^{-1}$ NAA. Flow cytometry analysis was used to identify the regenerated haploids. It also confirmed gynogenic occurrence at 1 and $2 \mathrm{mg} \cdot \mathrm{L}^{-1} 2,4-\mathrm{D}$ with percentages of $21.7 \%$ and $41 \%$, respectively. Therefore, 2,4-D proved effective for the induction of haploids in black cumin. The regenerated haploids were developed on MS medium without PGRs. The obtained results of in vitro gynogenesis and haploid plant production can tremendously facilitate breeding programs of black cumin.
\end{abstract}

Black cumin (Nigella sativa L.; $2 n=2 x=12$ ) is an annual flowering plant belonging to the Ranunculaceae family. In Islamic religion, Prophet Muhammad once stated that the black seed can heal every disease, except death. The plant has been used traditionally as a spice, as a food preservative, and for treatment of various diseases for centuries in the Middle East, Northern Africa and India
(Gilani et al., 2004). Several reports substantiated black cumin for its anticancer (Khan et al., 2011; Majdalawieh and Fayyad, 2016), immunomodulatory (Boskabady et al., 2011; Salem, 2005), and antiinflammatory activity (Chehi et al., 2009; Pise and Padwal, 2017). Many species and mutants (Chloroxantha mutant) of black cumin can be grown as ornamental plants in gardens (El-Mahrouk et al., 2015; Subrahmanyam, 2009). Production of homozygous populations by inbreed method, for hybrid breeding programs, is time- and money consuming for all plants. Alternatively, true homozygous lines can be obtained by the resulting haploid plant. Haploid, a plant that has a basic chromosome number [gametic chromosome number of diploid plant $(n)]$, represents a good method to accelerate plant breeding. Consequently, the importance of haploids is the production of pure lines [doubledhaploid $(\mathrm{DH})$ plants] by chromosome diploidization of haploids, which have many useful advantages such as direct generation of new cultivars in self-pollinated crops, produce high-yielding hybrids among pure line crosses, or both (Veilluex, 1994). Haploids can be originated spontaneously in nature or as a result of various induction techniques. In vitro culture techniques for haploid production such as male gametophytes (androgenesis) and female gametophytes (gynogenesis) were reported. There are more than 200 species of angiosperms that produce haploid plants through in vitro androgenesis (Małuszyński et al., 2003). The first production of haploid plants through in vitro gynogenesis of unfertilized ovaries culture was reported in barley (Hordeum vulgare) (San Noeum, 1976). In vitro induction of haploid plants from unpollinated ovules has been applied to several other crops and considered to be an alternative to anther culture technique in cases where anther culture has not been successful (Yang and Zhou, 1982). Haploid plants can be induced by parthenogenic development of the egg cell or other female gametophyte cells which lead to haploid or DH plant production (Forster et al., 2007). Moreover, diploid plants may be resulted from somatic cell besides haploid or DH plants, which can be produced by spontaneous diploidization, so that identification of regenerants' ploidy level is crucial. This can be done by various evaluation methods such as morphological traits of DH plants in the progeny (Murigneux et al., 1993; Rakha et al., 2012), isozymes (Kiełkowska and Adamus, 2010), molecular markers using restricted fragment length polymorphism (Murigneux et al., 1993), simple sequence repeats (Muranty et al., 2002), and flow cytometry (Kiełkowska and Adamus, 2010; Lotfi et al., 2003). The first use of DNA flow cytometry in plants was reported by Galbraith et al. (1983). The nuclei are classified according to their relative fluorescence intensity or DNA content (Dolezel and Bartos, 2005). DNA flow cytometry has become a popular method for ploidy screening, detection of mixoploidy, and aneuploid.

The previous reports studied the nutritional requirements and PGR effects for ovule formation in black cumin (Peterson, 1973, 1974). However, to our knowledge, there are no reports on haploid induction in black cumin. Therefore, this study is the first report on haploid production of black cumin from in vitro ovule culture. The aim of this study was to develop an efficient protocol for 
both in vitro gynogenesis embryo production and identification, using flow cytometry approaches.

\section{Materials and Methods}

Plant material and production of female flower buds. Pure line of diploid black cumin seeds resulting from three years of selfpollination were used as the plant material in this study (El-Mahrouk et al., 2015). Tetraploid seeds of black cumin were used in the comparative experiment by flow cytometry (Maamoun et al., 2014). Both diploid and tetraploid seeds were sown in the experimental farm of Kafrelsheikh University on the 15th of Oct. 2015 to obtain female flower buds. Donor plants were grown in open field conditions and all cultivation practices, i.e., plant density, irrigation, and fertilization were conducted according to Yimam et al. (2015).

Ovule culture establishment. Black cumin ovaries were picked one to $2 \mathrm{~d}$ before anthesis from 100 diploid plants and used directly or after exposing them to cold pretreatment at $4{ }^{\circ} \mathrm{C}$ for $5 \mathrm{~d}$ according to Lux et al. (1990). The fresh and cold-treated flowers were prepared by removing petals and style. Then, the ovaries were surface-disinfected for $2 \mathrm{~min}$ in $70 \%$ ethanol, followed by $15 \mathrm{~min}$ in a solution of $70 \%(\mathrm{v} / \mathrm{v})$ Clorox (sodium hypochlorite $0.05 \%, \mathrm{NaOCl}$ ) containing two to three drops of Tween-20 (Loba Chemical Company, Mumbai, Maharashtra, India). After three rinses with sterile distilled water, ovaries were dried on filter paper and the ovules were excised in a laminar flow cabinet. The ovules were cultured in a 7-cm petri dish containing MS (Murashige and Skoog, 1962) medium supplemented with $3 \%(\mathrm{w} / \mathrm{v})$ sucrose and different concentrations of BA, Kin, 2,4-D, and NAA at $0,0.5,1$, and $2 \mathrm{mg} \cdot \mathrm{L}^{-1}$. The media were solidified with $7.5 \mathrm{~g} \cdot \mathrm{L}^{-1}$ agar and the $\mathrm{pH}$ was adjusted to 5.7 before autoclaving at $121^{\circ} \mathrm{C}$ for $20 \mathrm{~min}$. MS basal medium without PGRs served as control. Each petri dish contained 25 ovules and all dishes were incubated at $25^{\circ} \mathrm{C}$ under dark conditions. The ovules were recultured after 3 weeks of incubation. After 6 weeks of culture, callus formation percentage, callus diameter, and direct embryogenesis percentage were recorded.

Gynogenesis and growth of haploid plantlets. Responded ovules were transferred to petri dishes (10 explants/petri dish) containing MS medium supplemented with

Received for publication 16 Jan. 2018. Accepted for publication 21 Feb. 2018.

This project was supported by Laboratory of Physiology and Breeding of Horticultural Crops, Faculty of Agriculture, Kafrelsheikh University, Egypt. The authors extend their appreciation to the Deanship of Scientific Research at King Saud University for funding this work through research group no. RGP-1438-012.

${ }^{1}$ Corresponding author. E-mail: threemelmahrouk@ yahoo.com.
$5 \mathrm{mg} \cdot \mathrm{L}^{-1} \mathrm{NAA}$ and $5 \mathrm{mg} \cdot \mathrm{L}^{-1} \mathrm{BA}$ according to El-Mahrouk et al. (2010). The cultures were incubated under dark conditions. After 8 weeks of culture, the number of embryo per ovule, the number of embryolike structures per callus, and the gynogenic percentage were recorded. The regenerated embryos and embryo-like structures were transplanted into MS medium without PGRs for their subsequent growth. The cultures were kept at $25{ }^{\circ} \mathrm{C}$ and $16-\mathrm{h}$ photoperiod at $35 \mu \mathrm{mol} \cdot \mathrm{m}^{-2} \cdot \mathrm{s}^{-1}$ photosynthetic photon flux density provided by fluorescent tubes. After 4 weeks of culture, survival percentage, plant height, number of leaves, and number of roots were recorded.

Ploidy level determination. The ploidy level of the regenerants was determined by an Attune flow cytometer (Applied Biosystem, CA). Samples were prepared from the young leaves according to the method of Galbraith et al. (1983). About $50 \mathrm{mg}$ leaf tissue was chopped and macerated in lysis buffer $(1 \mathrm{~mL})$ to release intact nuclei by razor blade in Galbraith buffer $[45 \mathrm{~mm} \mathrm{MgCl} 2 ; 30 \mathrm{~mm}$ sodium citrate; $20 \mathrm{~mm}$ MOPS; $0.1 \%(\mathrm{w} / \mathrm{v})$ Triton X-100; $\mathrm{pH}$ 7.0] for $1 \mathrm{~h}$. The cell suspensions were filtered through a $0.45-\mu \mathrm{m}$ nylon filter to eliminate cell debris for $5 \mathrm{~min}$ at room temperature. Then, the cell nuclei were stained with $10 \mu \mathrm{L} \mathrm{4} 4^{\prime}, 6^{\prime}$-diamino-2phenylidole (DAPI) solution (solution A of high-resolution kit type $\mathrm{P}$, Partec) for $30 \mathrm{~min}$ on ice in the dark. Leaves of diploid $(2 n=2 x=12)$ plants of black cumin were used as a reference standard. Nearly 10,000 nuclei were analyzed using a logarithmic scale. Histograms were analyzed using Attune cytometric software version 2.1.

Statistical analysis. In vitro experiments were set up in a completely randomized design and repeated twice. Each treatment consisted of three replications and each replication was represented by three petri dishes rendering a group of 75 ovules per treatment. Analysis of variance was conducted using SPSS (version 20) statistical

Table 1. Effect of plant growth regulators on callus induction and direct gynogenesis of black cumin ovules after 6 weeks.

\begin{tabular}{|c|c|c|c|c|}
\hline \multicolumn{2}{|c|}{ Treatment $\left(\mathrm{mg} \cdot \mathrm{L}^{-1}\right)$} & \multirow{2}{*}{$\frac{\text { Callus formation }(\%)}{0 \mathrm{c}^{\mathrm{z}}}$} & \multirow{2}{*}{$\frac{\text { Callus diam }(\mathrm{mm})}{0 \mathrm{c}}$} & \multirow{2}{*}{$\frac{\text { Direct gynogenesis }(\%)}{0 \mathrm{~b}}$} \\
\hline Control & 0.0 & & & \\
\hline \multirow[t]{3}{*}{$\mathrm{BA}$} & 0.5 & $0 \mathrm{c}$ & $0 \mathrm{c}$ & $0 \mathrm{~b}$ \\
\hline & 1.0 & $0 \mathrm{c}$ & $0 \mathrm{c}$ & $0 \mathrm{~b}$ \\
\hline & 2.0 & $0 \mathrm{c}$ & $0 \mathrm{c}$ & $0 \mathrm{~b}$ \\
\hline \multirow[t]{3}{*}{ Kin } & 0.5 & $0 \mathrm{c}$ & $0 \mathrm{c}$ & $0 \mathrm{~b}$ \\
\hline & 1.0 & $0 \mathrm{c}$ & $0 \mathrm{c}$ & $0 \mathrm{~b}$ \\
\hline & 2.0 & $0 \mathrm{c}$ & $0 \mathrm{c}$ & $0 \mathrm{~b}$ \\
\hline \multirow[t]{3}{*}{ 2.4-D } & 0.5 & $0 \mathrm{c}$ & $0 \mathrm{c}$ & $0 \mathrm{~b}$ \\
\hline & 1.0 & $100 \pm 0.00 \mathrm{a}$ & $4.7 \pm 0.057 \mathrm{~b}$ & $0 \mathrm{~b}$ \\
\hline & 2.0 & $66.6 \pm 0.88 b$ & $9.8 \pm 0.176 \mathrm{a}$ & $33.4 \pm 0.208 \mathrm{a}$ \\
\hline \multirow[t]{3}{*}{ NAA } & 0.5 & $0 \mathrm{c}$ & $0 \mathrm{c}$ & $0 \mathrm{~b}$ \\
\hline & 1.0 & $0 \mathrm{c}$ & $0 \mathrm{c}$ & $0 \mathrm{~b}$ \\
\hline & 2.0 & $100 \pm 0.00 \mathrm{a}$ & $4.5 \pm 0.29 b$ & $0 \mathrm{~b}$ \\
\hline Significant & & $* *$ & $* *$ & $* *$ \\
\hline LSD & & 0.743 & 0.028 & 0.175 \\
\hline
\end{tabular}

${ }^{\mathrm{z}}$ Mean separation within each column by Fisher's least significant difference (LSD) test at 5\% level. $\mathrm{BA}=$ benzyladenine; Kin = Kinetin; 2,4-D = 2,4-dichlorophenoxyacetic acid; NAA = naphthalene acetic acid.
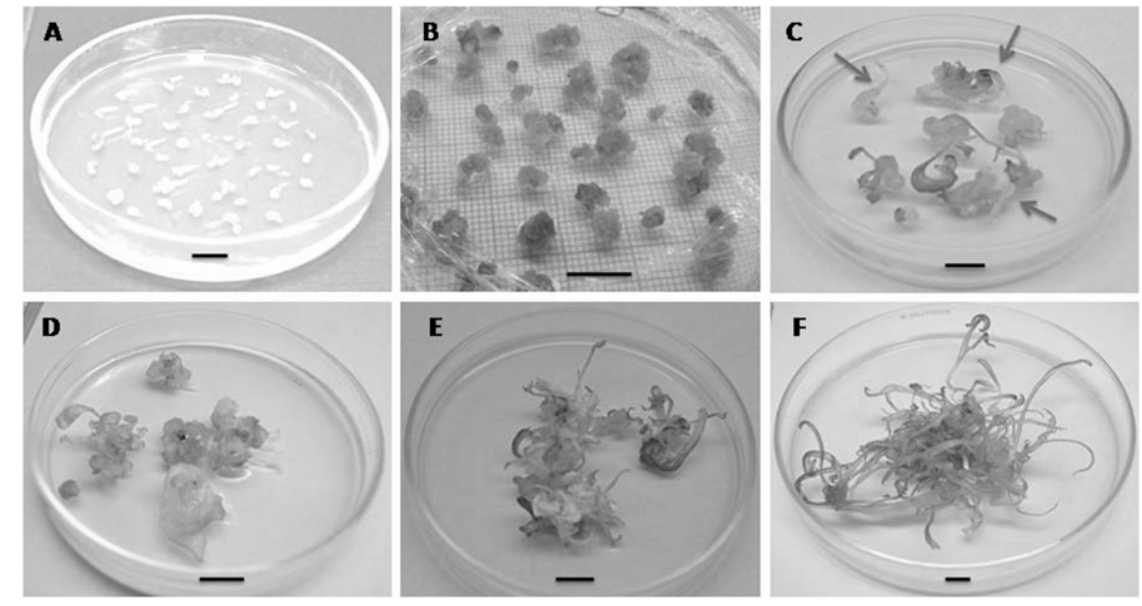

Fig. 1. In vitro production of black cumin haploids; (A) in vitro ovule culture, (B) callus induction of ovules, (C) embryogenesis of callus responded on $2 \mathrm{mg} \cdot \mathrm{L}^{-1}$ 2,4-D after 8 weeks (red arrows refer to direct embryos), (D) embryogenesis of callus responded on $1 \mathrm{mg} \cdot \mathrm{L}^{-1}$ 2,4-D after 8 weeks, (E) elongation of embryos on Murashige and Skoog (MS) medium without plant growth regulator (PGR), and (F) elongation of embryo-like structures on MS medium without PGR (bar $=1 \mathrm{~cm})$. 
program. The mean separations were carried out using Fisher's least significant difference test and significance was determined at $P \leq$ 0.05 , (Fisher, 1954). Data were presented as means \pm SE.

\section{Results and Discussion}

Effect of PGRs on callus induction and direct gynogenesis. The type of PGRs proved to be one of the most important factors influencing callus induction and direct embryogenesis in black cumin. The use of fresh flowers without cold pretreatment did not induce the ovule growth. Stress treatment is a common factor affecting gynogensis in many species (Kwack and Fujieda, 1988; Lux et al., 1990). Ovule growth induction was achieved only by using auxins at 1 and $2 \cdot \mathrm{mg} \cdot \mathrm{L}^{-1} 2,4-\mathrm{D}$ and $2 \mathrm{mg} \cdot \mathrm{L}^{-1} \mathrm{NAA}$ treatments (Table 1). Calluses were developed on the ovule surface within 3 weeks of culture (Fig. 1B). The callus subsequently covered the whole surface of the ovule by the end of 6 -week culture. The best result of callus formation $(100 \%)$ was obtained on the medium supplemented with $1 \mathrm{mg} \cdot \mathrm{L}^{-1} 2,4-\mathrm{D}$ and $2 \mathrm{mg} \cdot \mathrm{L}^{-1} \mathrm{NAA}$ followed by $2 \mathrm{mg} \cdot \mathrm{L}^{-1} 2,4-\mathrm{D}$, achieving $66.6 \%$ callus formation. On the other hand, no response was observed in all other treatments. The medium supplemented with $2 \mathrm{mg} \cdot \mathrm{L}^{-1}$ 2,4-D induced the highest callus growth (9.8 $\mathrm{mm}$ callus diameter), whereas the treatments of $1 \mathrm{mg} \cdot \mathrm{L}^{-1} 2,4-\mathrm{D}$ and $2 \mathrm{mg} \cdot \mathrm{L}^{-1} \mathrm{NAA}$ developed 4.7 and $4.5 \mathrm{~mm}$ callus diameter, respectively. The embryogenic calluses were developed on the surfaces of the ovules 6 weeks after culture initiation. It was observed that gynogenesis of black cumin ovules can be obtained directly on medium containing $2 \mathrm{mg} \cdot \mathrm{L}^{-1} 2,4-\mathrm{D}$ achieving 33.4\% (Table 1; Fig. 3C). Ovules of black cumin did not respond to cytokinin treatments and no growth could be achieved in the absence of auxins. This finding confirms previous results obtained by ElMahrouk et al. (2010) on Arbutus undeo, that the highest percentage of callus formation was observed on the medium containing NAA or 2,4-D. The previous study mentioned that 2,4-D is important for promoting and stimulating the formation of callus tissues (Kiełkowska and Adamus, 2010; Matsubara et al., 1995). Metwally et al. (1998) reported that the ovules producing embryogenic callus increases by increasing the auxin concentrations. In addition, 2,4-D has been proved effective for somatic embryogenesis in most plant species (Evans et al., 1981). According to Campion et al. (1992), 2,4-D gave the best result for haploid production of ovule, ovary, and whole flower bud of onion (Allium cepa). Haploid plants produced by gynogenesis can be regenerated directly or indirectly from callus (Keller and Korzun, 1996). All cells in the embryonic sac can be the main parts of direct gynogenesis that formed proembryos first and then differentiated to embryos (Akgo et al., 2017). On the other hand, callus can be formed directly from the egg cell, synergids, polar nuclei, and antipodals or can be developed from proembryos in indirect gynogenesis (Reed, 2005). Similar to our results, many studies mentioned that cold pretreatment of flower buds at $4{ }^{\circ} \mathrm{C}$ for $4-5 \mathrm{~d}$ led to increased embryo yield of sugar beet (Beta vulgaris) (Lux et al., 1990) and winter squash (Cucurbita moschata) (Kwack and Fujieda, 1988). However, in contrast to our results, ovules from flower buds without cold pretreatment showed a better embryogenic response in Cucurbita pepo (Gemes-Juhasz et al., 2002; Metwally et al., 1998). The results conclude that many factors can affect gynogenesis, including PGRs and cold pretreatment of flower buds and plant species.

Organogenesis of responded ovules. Under light conditions, all embryogenic calluses that formed on the surface of whole ovules developed into embryo-like structures (ELS) within 4 weeks of culture on organogenesis medium $\left(5 \mathrm{mg} \cdot \mathrm{L}^{-1} \mathrm{NAA}+5 \mathrm{mg} \cdot \mathrm{L}^{-1} \mathrm{BA}\right)$ (Figs. 1C and D and 2). Numerous small clumps of compact cells were developed into a mass of ELS. The highest number of ELS
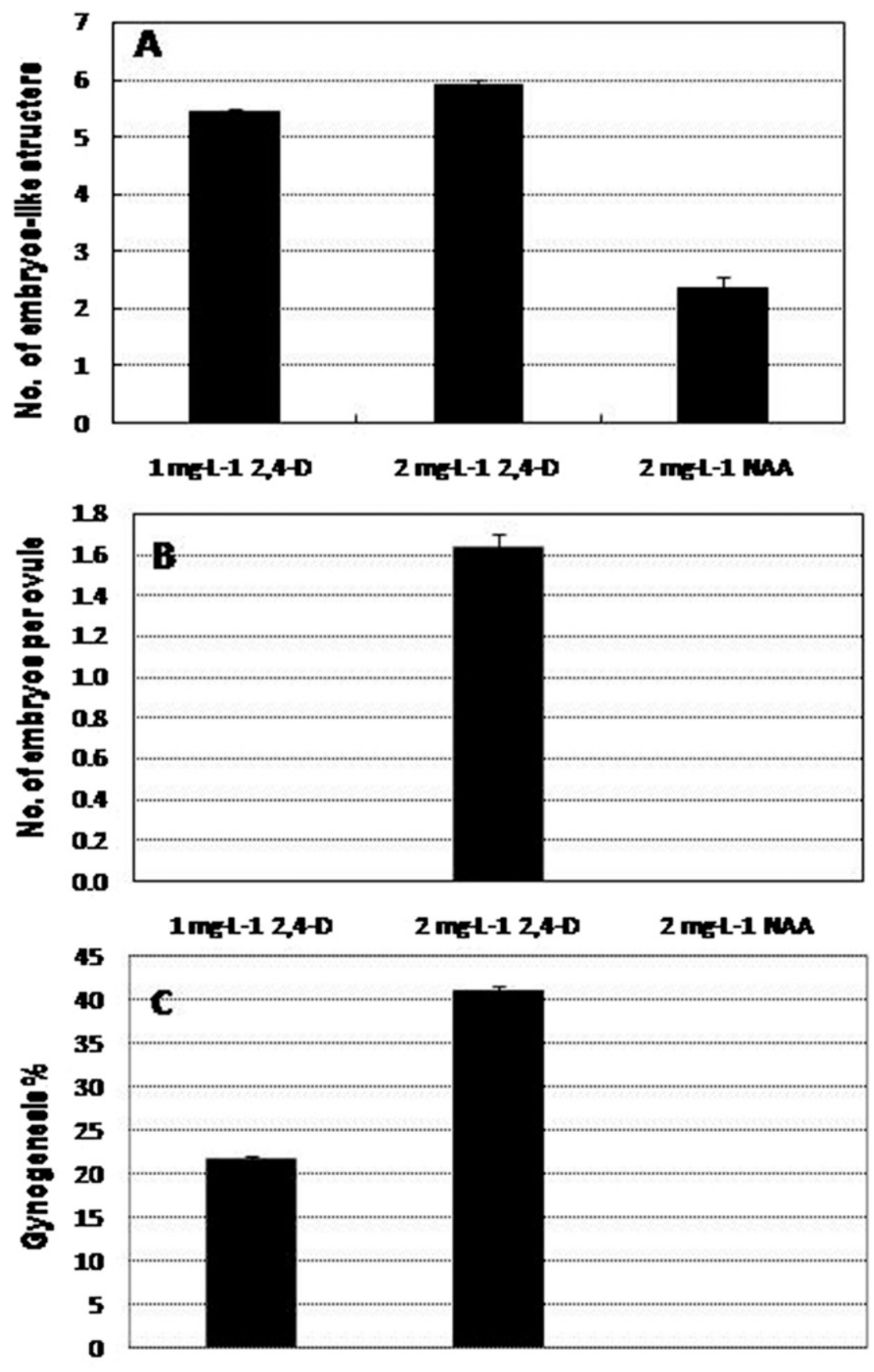

$1 \mathrm{mEt}-1$ 2,4-D

2 mg-t-1 2,4-D

2 mg-L 1 MaA

Fig. 2. Effect of auxins on gynogenesis of black cumin ovules after 8 weeks in culture; (A) number of embryo-like structures, (B) number of embryo per ovule, and (C) gynogenesis percentage. 
Table 2. Growth of the regenerated haploid embryos of black cumin on MS medium without PGRs.

\begin{tabular}{|c|c|c|c|c|}
\hline Treatment-derived embryos & Survival percentage (\%) & Number of leaves/plantlet & Number of root/plantlet & Plantlet ht $(\mathrm{cm})$ \\
\hline $2 \mathrm{mg} \cdot \mathrm{L}^{-1} \mathrm{NAA}$ & $0 \pm 0.00 \mathrm{c}$ & $0 \pm 0.00 \mathrm{c}$ & $0 \pm 0.00 \mathrm{c}$ & $0 \pm 0.00 \mathrm{c}$ \\
\hline Significant & $* *$ & ** & $* *$ & ** \\
\hline
\end{tabular}

${ }^{\mathrm{z}}$ Mean separation within columns by Fisher's least significant difference (LSD) test at $5 \%$ level.

MS = Murashige and Skoog; PGRs = plant growth regulators; 2,4-D = 2,4-dichlorophenoxyacetic acid; NAA = naphthalene acetic acid .

(5.93) was obtained from callus derived on MS medium supplemented with $2 \mathrm{mg} \cdot \mathrm{L}^{-1}$ 2,4-D, whereas the produced callus on media supplemented with $1 \mathrm{mg} \cdot \mathrm{L}^{-1} 2,4-\mathrm{D}$ or 2 $\mathrm{mg} \cdot \mathrm{L}^{-1} \mathrm{NAA}$ gave 5.43 and $2.36 \mathrm{ELS}$, respectively. It is well known that PGRs play important roles in plant cell division and differentiation. Nevertheless, PGRs that most widely affect organ regeneration, callus induction, or induce somatic embryogenesis are auxins and cytokinins (Nic-Can and Loyola-Vargas, 2016). In addition, auxin plays a central role in early and postembryogenic plant development (Cueva-Agila et al., 2016). Also, the combination of auxins and cytokinins was a prerequisite for indirect somatic embryogenesis of strawberry tree (Arbutus unedo) (El-Mahrouk et al., 2010). Direct somatic embryogenesis of black cumin ovules occurred only on medium containing $2 \mathrm{mg} \cdot \mathrm{L}^{-1} 2,4-\mathrm{D}$ with 1.63 embryo per ovule. Also, the best result of gynogenesis $(41 \%)$ was observed in ovules developed on the same medium, whereas the genogenic percentage at $1 \mathrm{mg} \cdot \mathrm{L}^{-1} 2,4-\mathrm{D}$ was $21.7 \%$. In contrast, the genogenic percentage could not be achieved for the enhanced ovules on medium containing NAA after subculturing on organogenesis medium. Although direct embryo frequency was low, this result seems to be advantageous in comparison with previous reports on ovule culture of black cumin, where no haploid embryo production was noticed (Peterson, 1973, 1974). Similar to our results, Kiełkowska and Adamus (2010) mentioned that in vitro-cultured ovules of carrot (Daucus carota) were doubled in size after $10 \mathrm{~d}$ and have a single embryo. Our results showed that all calluses responded positively on organogenesis medium; nevertheless, there were significant differences in the number of ELS or haploid and diploid embryo production. Although the callus derived on $2 \mathrm{mg} \cdot \mathrm{L}^{-1}$ NAA developed ELS, no haploid embryo was observed. The previous finding showed that a high percentage of diploids produced through indirect embryogenesis of unfertilized carrot ovules might be induced by high rates of spontaneous diploidization (Kiełkowska and Adamus, 2010). In addition, Dore and Boulidard (1988) reported that spontaneous diploidization occurring in vitro depends on different factors such as high concentrations of PGRs in the culture media and the type of in vitro culture. Also, spontaneous diploidization is common when plants are produced indirectly from callus tissues (Faris et al., 2000). Jensen (1986) mentioned that haploid nuclei fusion induced during the culture phase lead to an increase in
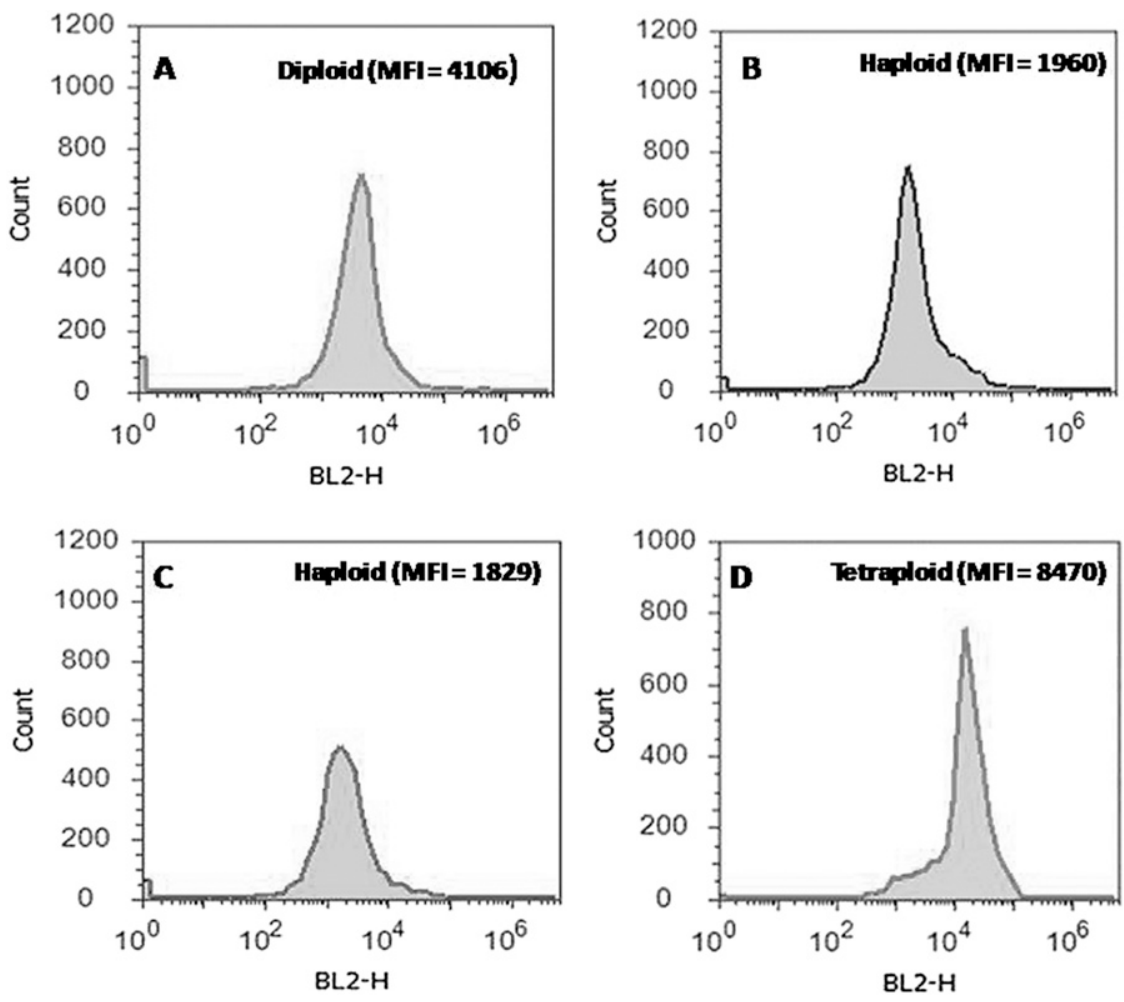

Fig. 3. Flow cytometric analysis based on median fluorescence intensity (MFI) of black cumin; (A) diploid plant, (B) haploid plant regenerated through direct gynogenesis of unfertilized ovule culture, $(\mathbf{C})$ haploid plant regenerated from callus of unfertilized ovule culture, and (D) tetraploid plant.

the number of chromosomes to form diploids, polyploids, and mixoploids. Therefore, the present work showed that callus derived on NAA-supplemented medium produce diploid regenerants. In general, Chen et al. (2011) showed that gynogenesis has two or more stages and each stage requires specific nutrition. The first stage is induction, where ovules and ovaries require low levels of PGRs and incubated in the dark or light according to plant species. The second stage is regeneration, where responded ovules are transferred to medium with higher PGR concentrations and incubated in light. In the present study, gynogenesis of black cumin required three stages as follows: induction on low concentrations of PGR, regeneration (organogenesis of callus) on high levels of PGR, and embryo elongation on MS medium without PGRs.

Growth and elongation of regenerated embryos. The regenerated shoots and ELS produced via indirect embryogenesis and direct embryos of ovules that were separated and cultured for 4 weeks on MS medium without PGRs showed the highest survival percentage of haploid embryos, which converted into plantlets with well-developed roots (Table 2; Fig. 1E and F). The highest survival percentage $(98 \%)$ of haploid plantlets on MS medium without PGRs was observed of regenerants that produced on induction medium containing $2 \mathrm{mg} \cdot \mathrm{L}^{-1}$ 2,4-D. Furthermore, haploid plantlets derived from the same induction medium had the highest vegetative growth with five leaves per plantlet, 2.4 roots per plantlet, and $4.2 \mathrm{~cm}$ in height. Using MS medium without PGRs for growth and elongation was successful in increasing the plantlet quality of Dieffenbachia maculata (El-Mahrouk et al., 2007) and Cordyline fruticosa (Dewir et al., 2015). Somatic embryos of strawberry tree cultured on MS medium without PGRs showed the highest somatic embryo conversion (96\%) into plantlets with well-developed roots (El-Mahrouk et al., 2007).

Ploidy level determination. To emphasis on ploidy level, flow cytometry of leaf tissue was used (Fig. 3). The histogram peak of median fluorescence intensity (MFI) of diploid plants was mentioned in 4106, whereas 


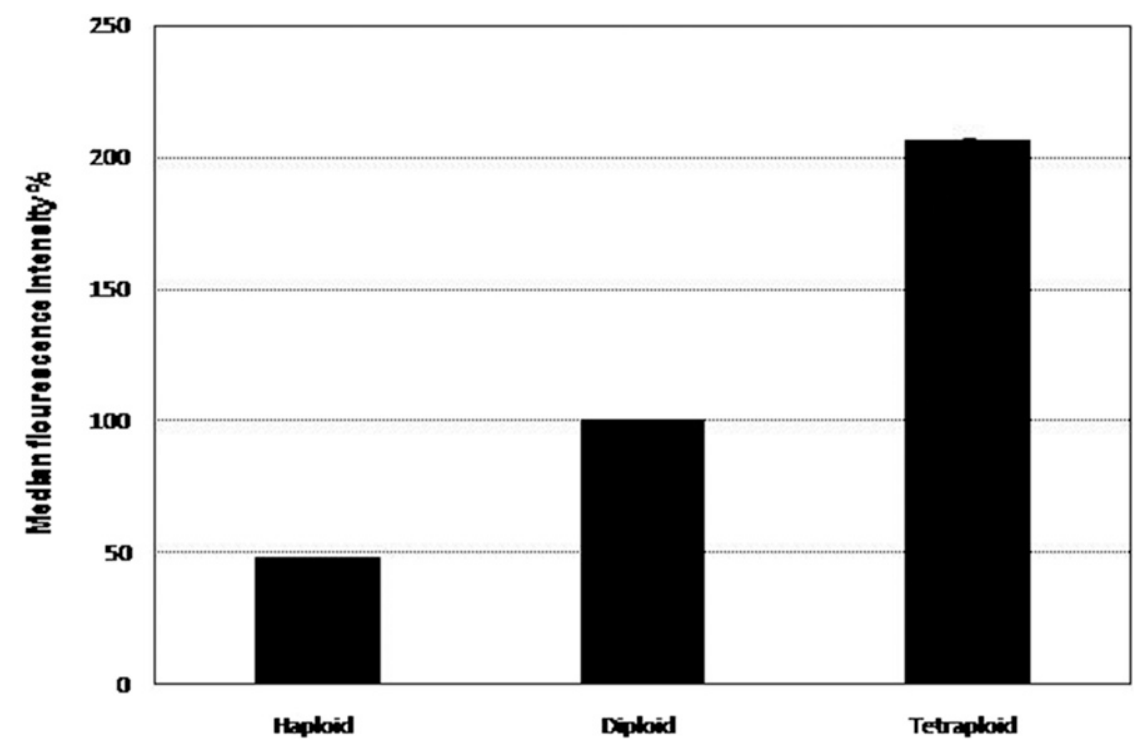

Fig. 4. Median fluorescence intensity percentage of haploid, diploid, and tetraploid as compared with diploid plant $(P \leq 0.001)$

the peaks of the in vitro-regenerated haploids were observed in 1960 and 1829 MFI for direct and indirect haploid plants, respectively. The histogram of tetraploid plants was observed in 8470 MFI. Flow cytometry data are displayed in the form of a histogram of relative fluorescence intensity, representing relative DNA content (Dolezel and Bartos, 2005). Therefore, plants which have MFIs with 1960 and 1829 are surely haploids when compared with diploid and tetraploid MFI. It is noted that MFI of haploid plants were near the value but not equal. The previous studies for using laser flow cytometry on sunflower (Helianthus annuus) of 13 diploids $(2 n=34)$ showed variability in mean DNA content exceeding $27 \%$ and $48 \%$ among leaves from different nodes of plants of the openpollinated variety and the inbred line, respectively (Michaelson et al., 1991). The variation of sunflower DNA content could be due to DNA-staining inhibitors effects (Price et al., 2000). Portugal and Waring (1988) mentioned that DAPI binds to adenine and thymine-rich regions, preferentially, so that numbers of cells that are not stained with DAPI did not release any fluorescence. Greilhuber $(1998,2005)$ suggested that the variation should be due to the material heterogeneity and nonequality of copy number of DNA sequences. Our results showed that MFI of haploid plants was nearly half diploid and the later nearly half tetrapliod (Fig. 4). Therefore, in vitro haploid regenerants were confirmed using flow cytometry. Gynogenesis percentages of $21.7 \%$ and $41 \%$ were obtained at 1 and $2 \mathrm{mg} \cdot \mathrm{L}^{-1} 2,4-\mathrm{D}$, respectively, whereas diploid was $59 \%$ and $78.3 \%$, respectively. More repeatability of diploid plants in black cumin should be due to high rates of spontaneous diploidization. The ability for spontaneous diploidization varies, depending on many factors (Kiełkowska and Adamus, 2010). In the present study, high percentages of diploids among direct and indirect embryogenesis regenerants of black cumin were observed. Kiełkowska and Adamus (2010) reported that in vitro carrot plants derived from ovule culture were $97.7 \%$ diploid, $2.2 \%$ polyploid $(3 \times, 4 \times$, $6 \times)$, and $0.1 \%$ haploid. Andersen et al. (1990) mentioned that $70 \%$ of obtained androgenic regenerants were diploids. The previous studies reported that flow cytometry was the best technique for ploidy level detection (Couto et al., 2013; Dolezel and Bartos, 2005; Kiełkowska and Adamus, 2010). They reported that flow cytometry has much higher relevance than any other proposed method for ploidy analysis of haploid regenerants

The present study reported a simple effective protocol for in vitro production of haploid plants. Among several PGR treatments, $2 \mathrm{mg} \cdot \mathrm{L}^{-1} 2,4-\mathrm{D}$ was optimal of direct gynogenesis, whereas $1 \mathrm{mg} \cdot \mathrm{L}^{-1} 2,4-\mathrm{D}$ resulted indirect gynogenesis. Flow cytometry analysis confirmed the production of haploids through in vitro gynogenesis. The reported results can facilitate breeding programs of black cumin in which haploids can be produced in a short time frame to generate homozygous lines.

\section{Literature Cited}

Andersen, S.B., I. Christiansen, and B. Farestveit. 1990. Carrot (Daucus carota L.): In vitro production of haploids and field trials, p. 393-402. In: Y.P.S. Bajaj (ed.). Biotechnology in agriculture and forestry, vol. 12. Haploids in crop improvement I. Springer, Berlin.

Akgo, M., O. Simsek, D. Donmez, and Y.A. Kacar. 2017. An overview of in vitro haploid plant production in Citrus. Amer. J. Plant Biol. 2:19-23.

Boskabady, M.H., R. Keyhanmanesh, S. Khameneh, Y. Doostdar, and M.R. Khakzad. 2011. Potential immune modulation effect of the extract of Nigella sativa on ovalbumin sensitized guinea pigs. J. Zhejiang Univ. Sci. B 12:201-209.

Campion, B., M.T. Azzimonti, E. Viani, M. Schiavi, and A. Falavigna. 1992. Advances in haploid plants induction in onion (Allium cepa $\mathrm{L}$.) through in vitro gynogenssis. Plant Sci. 86:97-104.
Chehi, N., G. Chipitsyna, Q. Gong, C.J. Yeo, and H.A. Arafat. 2009. Anti-inflammatory effects of the Nigella sativa seed extract, thymoquinone, in pancreatic cancer cells. HPB 11:373-381.

Chen, J., L. Cui, A.A. Malik, and K.G. Mbira. 2011. In vitro haploid and dihaploid production via unfertilized ovule culture. Plant Cell Tissue Organ Cult. 104:311-319.

Couto, E.G., L.M. Davide, F. Bustamante, R.G. Von Pinho, and T.N. Silva. 2013. Identification of haploid maize by flow cytometry morphological and molecular markers. Cienc. Agrotec. 37:25-31.

Cueva-Agila, A.Y., J. Medina, L. Concia, and R. Cella. 2016. Effects of plant growth regulator, auxin polar transport inhibitors on somatic embryogenesis and CMSERK gene expression in Cattleya maxima (Lindl.), p. 255-267. In: A. Mujib (ed.). Somatic embryogenesis in ornamentals and its applications. Springer, Delhi, India.

Dewir, Y.H., M.E. El-Mahrouk, and A.N. ELBanna. 2015. In vitro propagation and preliminary results of Agrobacterium-mediated genetic transformation of Cordyline fruticosa. S. Afr. J. Bot. 98:45-51.

Dolezel, J. and J. Bartos. 2005. Plant DNA flow cytometry and estimation of nuclear genome size. Ann. Bot. 95:99-110.

Dore, C. and L. Boulidard. 1988. Production de plantes androgenetiques de chou a choucroute (Brassica oleracea L. ssp. capitata) par culture d'antheres in vitro: Comportement des lignees haploids doubles (HD) et leurinteretcomme parents d'hybrides F1. Agronomie 8:851-862.

El-Mahrouk, M.E., Y.H. Dewir, and N. Singh. 2007. Indirect shoot organogenesis and plantlets regeneration from stem of ornamental Dieffenbachia maculata cv. Marianna. Acta Biol. Szeged. 51:113-116.

El-Mahrouk, M.E., Y.H. Dewir, and A. Omar. 2010. In vitro propagation of adult strawberry tree (Arbutus undeo L.) through adventitious shoots and somatic embryogenesis. Propag. Ornam. Plants 10:93-98.

El-Mahrouk, M.E., M.K. Maamoun, Y.H. Dewir, S.A. Omran, and A.N. EL-Banna. 2015. Morphological and molecular characterization of induced mutants in Nigella sativa L. using irradiation and chemical mutagens. Egypt. J. Plant Breed. 19:257-272.

Evans, D.A., W.R. Sharp, and C.E. Flick. 1981. Growth and behavior of cell culture: Embryogenesis and organogensis, p. 45-113. In: T.A. Thorpe (ed.). Plant tissue culture. Methods and applications in agriculture. Academic Press, New York, NY.

Faris, N.M., M. Rakoczy-Trojanowska, S. Malepszy, and K. Niemirowicz-Szczytt. 2000. Diploidization of cucumber (Cucumis sativus L.) haploids by in vitro culture of leaf explant, p. 49-54. In S. Bielecki, J. Tramper, and J. Polak (eds.). Food biotechnology. Elsevier, Amsterdam, The Netherland.

Fisher, R.A. 1954. Statistical methods for research workers. Oliver and Boyd, Edinburgh, ISBN 0-05-002170-2.

Forster, B.P., E. Heberle-Bors, K.J. Kasha, and A. Touraev. 2007. The resurgence of haploids in higher plants. Trends Plant Sci. 12:368-375.

Galbraith, D.W., K.R. Harkins, J.M. Maddox, N.M. Ayres, D.P. Sharma, and E. Firoozabady. 1983. Rapid flow cytometric analysis of the cell cycle in intact plant tissues. Science 220:1049-1051.

Gemes-Juhasz, A., P. Balogh, A. Ferenczy, and Z. Kristof. 2002. Effect of optimal stage of female gametophyte and heat treatment on in vitro gynogenesis induction in cucumber (Cucumis sativus L.). Plant Cell Rep. 21:105-111. 
Gilani, A., Q. Jabeen, and M. Khan. 2004. A review of medicinal uses and pharmacological activities of Nigella sativa. Pak. J. Biol. Sci. 7:441451.

Greilhuber, J. 1998. Intraspecific variation in genome size: A critical reassessment. Ann. Bot. 82:27-35.

Greilhuber, J. 2005. Intraspecific variation in genome size in angiosperms: Identifying its existence. Ann. Bot. 95:91-98.

Jensen, C.J. 1986. Haploid induction and production in crop plants, p. 231-256. In: W. Horn, C.J. Jensen, W. Odenbach, and O. Schreder (eds.). Genetic manipulation in plant breeding. Proceedings of Eucarpia. Walter de Gruvter, Berlin.

Keller, E.J. and L. Korzun. 1996. Ovary and ovule culture for haploid production, p. 217-235. In: S.M. Jain, S.K. Sopory, and R.E. Villeux (eds.). In vitro haploid production in higher plants. Vol. 1. Fundamental aspects and methods. Kluwer Academic Publishers, Dordrecht, The Netherlands.

Khan, M.A., H. Chen, M. Tania, and D. Zhang. 2011. Anticancer activities of Nigella sativa (black cumin). Afr. J. Tradit. Complement. Altern. Med. 8:226-232.

Kiełkowska, A. and A. Adamus. 2010. In vitro culture of unfertilized ovules in carrot (Daucus carota L.). Plant Cell Tissue Organ Cult. 102:309-319.

Kwack, S.N. and K. Fujieda. 1988. Somatic embryogenesis in cultured unfertilized ovules of Cucurbita moschata. J. Jpn. Soc. Hort. Sci. 57:34-42.

Maamoun, M.K.M., M.E. El-Mahrouk, Y.H. Dewir, and S.A. Omran. 2014. Effect of radiation and chemical mutagens on seeds germination of black cumin (Nigella sativa L). Agr. Technol. Thail. 10:1183-1199.

Majdalawieh, A.F. and M.W. Fayyad. 2016. Recent advances on the anti-cancer properties of Nigella sativa, a widely used food additive. J. Ayurveda Integr. Med. 7:173-180.

Małuszyński, M., K. Kasha, and I. Szarejko. 2003. Published doubled haploid protocols in plant species, p. 309-335. In: M. Małuszynski, K. Kasha, B. Forster, and I. Szarejko (eds.).
Doubled haploid production in crop plants. A manual. Kluwer Academic Publishers, Dordrecht, The Netherland.

Matsubara, S., N. Dohya, and K. Murakami. 1995. Callus formation and regeneration of adventitious embryos from carrot, fennel and mitsuba microspores by anther and isolated microspore cultures. Acta Hort. 392:129-137.

Metwally, E.I., S.A. Moustafa, B.I. El-Sawy, S.A. Haroun, and T.A. Shalaby. 1998. Production of haploid plants from in vitro culture of un pollinated ovules of Cucurbita pepo. Plant Cell Tissue Organ Cult. 52:117-121.

Michaelson, M.J., H.J. Price, J.S. Johnston, and J.R. Ellison. 1991. Variation of nuclear DNA content in Helianthus annuus (Asteraceae). Amer. J. Bot. 78:1238-1243.

Muranty, H., P. Sourdille, S. Bernard, and M. Bernard. 2002. Genetic characterization of spontaneous diploid androgenetic wheat and triticale plants. Plant Breed. 121:470-474.

Murashige, T. and F. Skoog. 1962. A revised medium for rapid growth and bioassay with tobacco tissue culture. Physiol. Plant. 15:473-495.

Murigneux, A., D. Barloy, P. Leroy, and M. Beckert. 1993. Molecular and morphological evaluation of doubled haploid lines in maize. 1. Homogeneity within DH lines. Theor. Appl. Genet. 86:837-842.

Nic-Can, G.I. and V.M. Loyola-Vargas. 2016. The role of the auxins during somatic embryogenesis. In: V. Loyola-Vargas and N. Ochoa-Alejo (eds.). Somatic embryogenesis: Fundamental aspects and applications. Springer, Cham, Switzerland.

Lotfi, M., A.R. Alan, M.J. Henning, M.M. Jahn, and E.D. Earle. 2003. Production of haploid and doubled haploid plants of melon (Cucumis melo L.) for use in breeding for multiple virus resistance. Plant Cell Rep. 21:1121-1128.

Lux, H., L. Herrman, and C. Wetzel. 1990. Production of haploid sugar beet (Beta vulgaris L.) by culturing unpollinated ovules. Plant Breed. 104:177-183.

Peterson, C.M. 1973. Nutritional requirements for ovule formation in excised pistils of Nigella. Amer. J. Bot. 60:381-386.
Peterson, C.M. 1974. The effects of gibberellic acid and a growth retardant on ovule formation and growth of excised pistils of Nigella sativa (Ranunculaceae). Amer. J. Bot. 61:693-698.

Pise, H.N. and S.L. Padwal. 2017. Evaluation of anti-inflammatory activity of Nigella sativa: An experimental study. Natl. J. Physiol. Pharm. Pharmacol. 7:707-711.

Portugal, J. and M.J. Waring. 1988. Assignment of DNA binding sites for 4',6-diamidino-2phenylindole and bisbenzimide (Hoechst 33258). A comparative foot printing study. Biochim. Biophys. Acta 949:158-168.

Price, H.J., G. Hodnet, and J.S. Johnston. 2000. Sunflower (Helianthus annuus) leaves contain compounds that reduce nuclear propidiumiodide fluorescence. Ann. Bot. 86:929-934.

Rakha, M.T., E.I. Metwally, S.A. Moustafa, A.A. Etman, and Y.H. Dewir. 2012. Evaluation of regenerated strains from six Cucurbita interspecific hybrids obtained through anther and ovule in vitro cultures. Austral. J. Crop Sci. 6:23-30.

Reed, S.M. 2005. Haploid cultures, p. 225-234. In: R.N. Trigiano and D.J. Gray (eds.). Plant development and biotechnology. CRC Press, Boca Raton, FL.

San Noeum, L.H. 1976. Haploidesd' Hordeum vulgare par culture in vitro d'ovaires non fe'condes. Ann. Ame'liar. Plantes 26:751-754.

Salem, M.L. 2005. Immunomodulatory and therapeutic properties of the Nigella sativa L. seed. Intl. J. Immunopharmacol. 5:1749-1770.

Subrahmanyam, N.S. 2009. Modern plant taxonomy. Publishing House Pvt, Ltd, New Delhi, India.

Veilluex, R.C. 1994. Development of new cultivars via anther culture. HortScience 29:1238-1241.

Yang, H.Y. and C. Zhou. 1982. In vitro induction of haploid plants from unpollinated ovaries and ovules. Theor. Appl. Genet. 63:97-104.

Yimam, E., A. Nebiyu, A. Mohammed, and M. Getachew. 2015. Effect of nitrogen and phosphorus fertilizers on growth, yield and yield components of black cumin (Nigella sativa L.) at Konta district, south west Ethiopia. J. Agron. $14: 112-120$. 